\title{
Comparative Study on the Efficacy of Amprolium and Sulfadimidine in Coccidia Infected Chickens in Debre- Zeit Agricultural Research Center Poultry Farm, Bishoftu, Ethiopia
}

\author{
Abdisa Hunduma ${ }^{1}$, Bedaso Kebede ${ }^{1 *}$ \\ ${ }^{1}$ Veterinary Drug and Animal Feed Administration and Control Authority, Ministry of Livestock and Fisheries
}

Received: 30 September 2016; Accepted: 17 October 2016; Published: 27 October 2016

*Corresponding author: Bedaso Kebede, Veterinary Drug and Animal Feed Administration and Control Authority, Ministry of Livestock and Fisheries, Ethiopia; E-mail: Kebede.bedaso@yahoo.com

\begin{abstract}
An experimental type of study was conducted to assess the efficacy of Amprolium and Sulfadimidine drugs in the treatment of chickens' coccidiosis at Debre-zeit Agricultural Research Center poultry farms. Total 52 chickens were purposively selected for this study. Among them 17 chickens were used for control group while 35 chickens were used for treatment group. The thirty five chickens used for treatment group were 18 of them treated with Amprolium and the rest 17 were treated with Sulfadimidine. The drugs were administered orally in drinking water. The treatment response of these drugs for coccidiosis with respect to reduction in fecal scores (OPG count) was done by comparing OPG count before and after treatment. This fecal Oocyst count (OPG count) was conducted by using the modified McMaster Oocyst count. The mean OPG count between before treatment and after treatment was 3288.8 and 1468.65 respectively. This result denotes that the OPG count after treatment was not significantly reduced $(p>0.05)$ when compared with OPG count before treatment. The OPG count between before and after treatment was statistically significant difference $(\mathrm{p}<$ 0.05 ). The current findings of the study showed as there was no statistically significant difference in OPG count between before and after treatment in Amprolium treated groups ( $p>0.05$ ), but in the Sulfadimidine administered group, there was statistically significant difference $(p=0.004)$. This reveals that Sulfadimidine is more effective than Amprolium to treat coccidial infection. Adequate measures must be taken to avoid coccidiosis outbreaks; otherwise it will continue to cause considerable losses to the poultry industry particularly when favorable conditions for the parasite development are created.
\end{abstract}

Keywords: Amprolium; Coccidian; Eimeria; OPG Count; Sulfadimidine

\section{Abbreviation}

CSA: Central Statistical Authority; DZARC: Debre-zeit Agricultural Research Center; EARO: Ethiopian Agricultural Research Organization; FAO: Food and Agricultural Organization; Kca: Kilo caloric; NOAH: National Office of Animal Health; OPG: Oocyst Per gram feaces; Rpm: Revolution per minute; SPSS: Statistical Package for Social Science; USA: United States of America

\section{Introduction}

Poultry refers to all domestic birds such as chickens (domestic fowl), turkeys, ducks, geese, guinea fowls, ostriches and others, which are mainly kept for the production of meat and egg for human consumption. Among these, chickens are the most important species, adapted globally to various climatic conditions where human being lives and play a significant role in supplying animal origin protein to improve the nutrition of human being [1].

In developing countries, the raising of chickens contributes an opportunity to feed the rapid growing of human population and generate income for poor farmers. In addition, poultry in several parts of the modern world is considered to be the chief source of animal origin protein and high quality for human consumption [2].

Population of poultry in Ethiopia estimated to be 42 million excluding pastoral and agro-pastoral areas [2]. Among those only $1 \%$ is raised under intensive management system while the remaining $99 \%$ are raised under back yard or traditional low input production system which losses revenues and food subsistence in the country [3]. Indigenous chickens in Ethiopia are predominantly raised where free range scavenging management system is practiced and thus birds are left to depend primarily on what nature offers [4]. On the other hand, the current trend indicates the improved breeds kept under small scale poultry farm especially in and around Addis Ababa, Bishoftu and Adama [5].

Diseases and management problems become extremely important both in the commercial and backyard production system. In rural Ethiopia the main constraints for the improvement of local poultry production systems are diseases, predation, malnutrition, housing and poor management system [6]. Chickens' prevalent diseases in Ethiopia are Newcastle disease, Coccidiosis, Salmonellosis, chronic respiratory disease and nutritional deficiency. Poultry mortality due to disease is 
estimated between $20-50 \%$ but can go as high as $80 \%$ during time of epidemics. Among those diseases, the parasitic protozoan disease coccidiosis is economically important and prevalent in chicken farm in Ethiopia [3]. Parasitic diseases are of particular importance because of their high incidence in poultry occasioned by the tropical environmental conditions under which the farmer operates [7].

The disease of coccidiosis is caused by the Phylum Sporozoa, with few exceptions the organisms are intracellular parasites of intestinal epithelium [8]. The Coccidia occurring in poultry belongs almost exclusively to the genus Eimeria [9]. In chicken, coccidiosis is caused by nine species of Eimeria among which six species such as E.tenella, E. necatrix, E. brunetti, E. maxima, E. acervulina, and E. mivati produce moderate to severe intestinal or caecal lesions where as E. praecox, E. hagani and E. mitis do not produce significant lesions [7]. According to [12]; [13] nine species of Eimeria have been described in chickens; seven are currently recognized as valid: Eimeria acervulina, Eimeria praecox, Eimeria maxima, Eimeria mitis, Eimeria necatrix, Eimeria tenella, Eimeria brunetti. While Eimeria tenella causes caecal coccidiosis, the rest are known to cause intestinal coccidiosis [12]. Among the nine (9) species of coccidian affecting the chickens, Eimeria tenella and Eimeria maxima are the most common species [14]. Coccidial infections in chicken causes considerable economic losses than in other domesticate birds and it is caused by the genus Eimeria and nine species are known to occur in chicken, which are widely distributed throughout the world [15]. Coccidiosis remains one of the major disease problems of poultry in spite of advances made in prevention and control through chemotherapy, management and nutrition [16].

In Ethiopia Coccidiosis is endemic, causing great economic losses particularly in young growing birds in all production system. Quantitative losses due to Coccidiosis in Ethiopia are not well documented, but [17] has reported that Coccidiosis contributes to $8.4 \%$ loss in profit in large scale farms and $11.86 \%$ loss in profit in small scale farms. The success of poultry rearing is mainly dependent on improved management, improved nutritional status and effective disease prevention and control measures [18].

A succession of chemical compounds has been introduced and has been crucial in the successful control of coccidiosis in the rapidly expanding poultry industries throughout the world. However, the emergence of resistance has been rapid and has limited the useful life of many chemical anticoccidial drugs. Although the speed at which resistance develop varies greatly between compounds, continuous use of anticoccidial drugs promotes the emergence of drug resistant strains of coccidian. Despite the economic significance of the disease no major research work has been done to determine the treatment response of poultry coccidiosis (to evaluate the drug efficacy) in Ethiopia. Therefore, the objective of this study was to assess and compare the efficacy of Amprolium and Sulfadimidine used for treatment of poultry coccidiosis.

\section{Materials and Methods \\ Study area and population}

The study was conducted in the poultry farm of Ethiopian Agricultural research centre at Bishoftu. This poultry farm has many breeds of chickens such as Local (Horo), Cross, Dominant, Fayoumi, Kokock and Hubbard classic. The farm rears these chickens in 10 different houses and it has its own hatchery and incubation room. Bishoftu is located about 47 kilometers South East of Addis Ababa. The area is located at about 1850 meters above sea level. The town has the population of about 95,000 people. The soil and climate of the area are similar to those in many highland areas in Ethiopia. The main rainy season of the area ranges from June to September with an average rain fall of 800 millimeters, of which $84 \%$ of the rain is expected. There is also a short rainy season from March to May. The annual average temperature ranges from $12.3^{\circ} \mathrm{C}$ to $27.7^{\circ} \mathrm{C}$ with an average temperature of $18.7^{\circ} \mathrm{C}$. The highest temperature is reached in May [19]. The study was carried out on different breeds of chickens reared in six poultry houses at the Ethiopian Agricultural research centre poultry farm. The study covered the breeds such as Cross, Dominant, Fayoumi, Horo and Kokock with their numbers 6, 6, 12,14 and 14 respectively.

\section{Study Design, Sampling and Methods}

An experimental type of study design was conducted to assess the treatment response of the Coccidiosis to the Amprolium and Sulfadimidine drugs. Chickens used in this experiment were selected purposively. The study was conducted on the freshly collected fecal sample from each control and treatment group (before treatment and after treatment with Amprolium and Sulfadimidine) of chickens. In the study 35 chickens were used for drugs treatments as treatment group, 18 of them were treated with Amprolium and 17 of them were treated with Sulfadimidine. The rest of 17 Chickens were used as control group. Fecal Oocyst count (OPG count) was conducted as indicated [20] by using modified McMaster Oocyst count to compare the efficacy of the Amprolium and Sulfadimidine. The OPG count was performed before and after treatment to evaluate the efficacy of the drugs by comparing the OPG count before and after treatment. Amprolium and Sulfadimidine were administered after the chickens in each pen were grouped into treatment and control groups. These drugs were administered for the treatment group with drinking water with the dose of 1 gram per liter of water for Amprolium and 3 milliliter per liter of water in case of Sulfadimidine and the administration continued for 7 and 5 days respectively. The OPG count after treatment was conducted after 7 days for Amprolium and after 5 days for Sulfadimidine.

\section{Data Analysis}

The data was entered into computer using Excel spreadsheet. It was then analyzed using SPSS soft ware. A chi-square test was used to analyze the data. The results of this study were considered as significant when a $P$ value was less than 0.05 . 


\section{Results}

The mean of Fecal Oocysts count (OPG count) before treatment and after treatment was 3288.08 and 1468.65 respectively (Table 1). There was statistically significant difference $(P<0.05)$ in $O P G$ count between before treatment and after treatment and OPG count after treatment was significantly reduced.

The mean difference between OPG counts before and after treatment of Amprolium and Sulfadimidine were 4691.11 and 2915.00; 4126.47 and 454.12 respectively. Treatment of Amprolium before and after was statistically insignificant ( $p$ $>0.05$ ), but treatment of Sulfadimidine before and after was statistically significant $(\mathrm{p}<0.05)$ (Table 2$)$.

The percentages of the study conducted on poultry breeds of Cross, Dominant, Fayoumi, Horo (Local), and Kokock were $26.9 \%, 1.5 \%, 11.5 \%, 26.9 \%$, and $23.1 \%$ respectively (Table 3 ).

\section{Discussion}

The current study was undertaken to assess and compare the efficacy of Amprolium and Sulfadimidine in naturally coccidia infected chickens in Ethiopian Agriculture research center poultry farm. In this study, the modified McMaster Oocyst count (OPG count) was used to compare the efficacy of drugs. The mean of Fecal Oocysts count (OPG count) before treatment and after treatment was 3288.08 and 1468.65 respectively. There was statistically significant difference $(\mathrm{P}<0.05)$ in $\mathrm{OPG}$

Table 1: Comparison of OPG count before treatment and after treatment

\begin{tabular}{|l|c|c|c|c|c|}
\hline & Mean & $\begin{array}{c}\text { Total } \\
\text { number } \\
\text { of sample } \\
\text { (N) }\end{array}$ & $\begin{array}{c}\text { Std. } \\
\text { Deviation }\end{array}$ & $\begin{array}{c}\text { Std. } \\
\text { Error }\end{array}$ & Significance \\
\hline $\begin{array}{c}\text { OPG count } \\
\text { before } \\
\text { treatment }\end{array}$ & 3288.08 & 52 & 6214.391 & 861.781 & 0.010 \\
\hline $\begin{array}{c}\text { OPG count } \\
\text { after } \\
\text { treatment }\end{array}$ & 1468.65 & 52 & 3346.899 & 464.131 & \\
\hline
\end{tabular}

Table 2: Comparison of OPG count before and after treatment between Amprolium and Sulfadimidine

\begin{tabular}{|l|l|l|l|l|l|l|}
\hline Drug used & $\begin{array}{l}\text { Before } \\
\text { / after } \\
\text { treated }\end{array}$ & Mean & N & $\begin{array}{l}\text { Std. } \\
\text { deviation }\end{array}$ & Std. Error & significance \\
\hline Amprolium & $\begin{array}{l}\text { OPG count } \\
\text { before } \\
\text { treatment }\end{array}$ & 4691.11 & 18 & 8948.783 & 2109.248 & 0.283 \\
\hline & $\begin{array}{l}\text { OPG count } \\
\text { after } \\
\text { treatment }\end{array}$ & 2915.00 & 18 & 5039.440 & 187.807 & \\
\hline Sulfadimidine & $\begin{array}{l}\text { OPG count } \\
\text { before } \\
\text { treatment }\end{array}$ & 4126.47 & 17 & 5013.994 & 1216.072 & 0.004 \\
\hline & $\begin{array}{l}\text { OPG count } \\
\text { after } \\
\text { treatment }\end{array}$ & 454.12 & 17 & 821.942 & 199.350 & \\
\hline
\end{tabular}

Table 3: Frequencies and percent of breeds used in the study

\begin{tabular}{|c|c|c|}
\hline Breed & Frequencies & Percent (\%) \\
\hline Cross & 14 & 26.9 \\
\hline Dominant & 6 & 1.5 \\
\hline Fayoumi & 6 & 11.5 \\
\hline Horo (local) & 14 & 26.9 \\
\hline Kokock & 12 & 23.1 \\
\hline Total & 52 & 100.00 \\
\hline
\end{tabular}

count between before treatment and after treatment and OPG count after treatment was significantly reduced. Report by [12] Compare the efficacy of Diclazuril and Amprolium in naturally infected broilers in Uganda. In that study they found that there was a significant reduction $(\mathrm{P}<0.05)$ by ANOVA in the mean OPG counts of the treatment and control groups.

The mean difference between OPG counts before and after treatment of Amprolium and Sulfadimidine were 4691.11 and 2915.00; 4126.47 and 454.12 respectively. Treatment of Amprolium before and after was statistically insignificant ( $p$ $>0.05$ ), but treatment of Sulfadimidine before and after was statistically significant $(p<0.05)$. Based on this, Sulfadimidine had higher efficacy than Amprolium. This could be due to the fact that Amprolium have been in use in this poultry farm over many years and resistance to it might have developed as it is claimed. On the other hand, even if sulfonamides were the primary drugs for the treatment of coccidiosis in many parts of the world; Sulfadimidine is a more recently used for the treatment of coccidiosis in this poultry farm and it is less likely to show resistance. Continuous use of anticoccidial drugs has led to ineffective treatment due to drug resistance in the target parasites population. Drug resistance is heritable and depends on the amount of Oocysts discharged from infected chickens depends on the dose of Oocysts ingested and the immunological status acquired from pre- exposure (re-infection) [21]. According to [22] some studies in the floor pens and the field indicate that chickens given various drug programmes can develop immunity when exposed to natural infections. The greater or lesser extent of interference of anticoccidial drugs is not barrier to the development of immunity to Eimeria species. Therefore, the acquisition of immunity is a real possibility as long as sufficient parasites are present in the environment. Eventhough, anticoccidial drugs over a long time may lead to emergence of drug resistant population of coccidian. For this matter, it is important to review or change the medicine used as coccidiosis start from time to time [1]. Drug resistance mechanism involves either difference in drug metabolism within the parasite or mutations at the binding site of the drugs [23]. As indicated in the previous study Amprolium and Sulfaquinoxaline which is sulfonamide group have been used intensively in Nigeria for over two decades and there have been a development of resistance to the two drugs in the field [24]. There was also a study conducted in Nigeria by [25] to compare the efficacy of Toltrazuril, Amprolium and Embazine Fort. In that study, 
Toltrazuril had higher efficacy than Amprolium and Embazine Fort. The reason set for that was Amprolium and Embazine Fort have been in use in Nigeria for over two decades and there had been a development of resistance to the drugs, while Toltrazuril was a more recently introduced drug to Nigeria and was therefore less likely to show resistance. [22] Had also reported wide spread of resistance to most drugs in use today including Amprolium and Sulfonamides.

The control of avian coccidiosis mainly relies almost entirely on chemotherapy, as it is evidenced from the fact that most intensively reared chickens are fed an anticoccidial agent in the diet throughout their growth periods. Feed or water medication is a convenient and cost effective method of enabling large numbers of chickens to be reared under intensive conditions. The practice of including drugs in the feed or water throughout the life of the bird has ensured that few parasites escape the effect of medication. In such an environment parasites are exposed throughout their life cycle to agents designed for their removal and this has inevitably resulted in the development of resistance [23].

It has been shown that parasites resistant to the recommended levels of certain anticoccidial drugs may be suppressed if the concentration of drug is increased. Resistance to this higher concentration, however, is likely to develop rapidly after further selection. Increasing the concentration of a drug may therefore, be the only use in the short term and in any case, would not be practical because most anticoccidial drugs are used at a level close to those that are toxic to the chicken. But, resistant strains may emerge if anticoccidial drugs have been used at concentrations lower than those normally recommended for control [23].

\section{Conclusion and Recommendations}

1. The current study concluded that Sulfadimidine is the better option for the treatment of poultry coccidiosis than Amprolium in the study area. Commonly coccidiosis is treated with water soluble drugs such as Sulphonamides, Amprolium, Diclazuril and Toltrazuril. This water medication is convenient and can be rapidly given. The resistant strains of coccidia may emerge if anticoccidial drugs have been used at a concentration lower than those normally recommended for use. The importance of the use of anticoccidial drugs to which resistance is not developed have been emphasizing in the present experiment. Therefore, based on the above conclusions, the following recommendations are forwardedRational use of anticoccidial drugs in the treatment of chickens to reduce the development of drug resistance.

2. Further studies with better facilities and larger area coverage should be conducted.

3. Immunization activities against chickens' coccidiosis should be done.

4. In any poultry farm there should be strict biosecurity measures.

\section{Acknowledgment}

We authors thanks Bishoftu research Center for their assistance during this study.

\section{Conflict Of Interest}

We authors Declare that no interest conflict.

\section{References}

1. Chauhan S, Roy S. Poultry Diseases. Diagnosis and treatment, 3rd Ed., New age international ptd, publishers, New Delhi. 2007:152-156.

2. EARO: Animal Science research strategy directorate. Poultry research strategy. Addis Ababa, 200, 2000;1-33.

3. CSA, Central Statistical Authority: Ethiopian livestock Estimates. Vol.1, bulletin 52. Addis Ababa, Ethiopia.2004.

4. Alamargot J. Avian pathology of industrial farms in Ethiopia. First national livestock conference, Addis Ababa, Agricultural research institute. In: IAR proceeding. 1987;114-117.

5. Yami A, Tadelle D. The Status of Poultry Research and Development in Ethiopia. DZARC Research Bulletin. 1997; 4: 40-46.

6. Alemu Y. Poultry production in Ethiopia. World's Poultry Science Journal. 1995;51(2):197-201. doi: 10.1079/WPS19950014.

7. Alemu Y, Tadelle D. The state of poultry research and development in Ethiopia. Polt. Res. Bull. Debrezeit Eth. 1997;4:1-62.

8. Seifert, H.Tropical Animal Health. 3rd Ed., Kluwee academic Publishers, Boston. 2006;57.

9. Urquhart M, Armour J, Duncan L, Dunn M,Jennings, W. 1989; Veterinary

10. Gordon, R. F, Jordan F,J. W.Poultry disease. 2nd Ed. London, Baillier Tindal, 1982;123-141.

11. Chauhan S, Roy S. Poultry Diseases. Diagnosis and treatment, 3rd Ed. New age international ptd, publishers, New Delhi. 2007:152-156.

12.G. Mukiibi-Muka, M O Otim, G Musisi, J Illango, T Galiwango, et.al. Comparative study on the efficacy of Diclazuril and Amprolium in naturally infected broilers in Uganda. Revue Elev Méd. Vét. Pays trop. 2001;54(1):33-35.

13. Badran I , Lukešová D. Control of Coccidiosis and Different Coccidia of Chicken in Selected Technologies Used In Tropics and Subtropics. Agr Trop. ET Subtrop. 2006;39(1):1-39.

14. Adewole, O Ado-Ekiti Nigeria. The Efficacy of Drugs in the Treatment of Coccidiosis in Chicken in Selected Poultries. Ekiti State University. 2012;2(1):1-3.

15. Reid, W.M. Coccidiosis, disease of poultry. 7th Ed., Iowa state University press. Ames, Iowa, USA. 1978;784-805.

16. Graat EA, Ploeger HW , Henken AM , De Vries Reilingh G , Noordhuizen JP , et.al. G.Effects of initial litter contamination level with Eimeria Acervulina in population Dynamics and production characteristics in Broilers. Vet. Para. 1996; 65(3-4):223-232.

17.Safari, M. Study on prevalence and Economic Impact of poultry Coccidiosis in different production system in Debrezeit and Addis Ababa, Ethiopia. Faculty of veterinary Medicine, Free University of Berlin, Debrezeit/Berlin, Msc theses. 2001;3-5.

18. M. Nasser, J. E. Lohr , G. Y. Mebratu , K.-H. Zessin , M. P. O. Baumann \& Z.Oral new castle disease Vaccination trials and studies on new castle Disease in Ethiopia, MSC Thesis. FVM, AAU and Freie University, Berlin.1998;29(1):27-34. doi: 10.1080/03079450094243. 
19. CSA, Central Statistical Authority: Federal Democratic Republic of Ethiopia, Central Statistical Investigatory, Statistical abstract. 2001.

20. Permin A, Hansen W. Epidemiology, Diagnosis and control of poultry parasites. Food and agricultural organization of the United Nations, Animal health manuals. Rome. 1998;4:160.

21. Getachew G, Getachew T, Dorchies. Study on Poultry Coccidiosis in Tiyo District, Arsi Zone, Ethiopia. Int J. Poult Sci. 2008;7:251-256.

22. Chapman, H. D. Anticoccidial drugs and their effects upon the development of immunity to Eimeria infections in poultry. Avi. Path. 1999;28(6):521-535. doi:10.1080/03079459994317.
23. Taylor A, Coop L, Wall, L. Veterinary Parasitology. 3rd Ed., Black well publishing Ltd, USA. 2007;776-799.

24.GN Anosa , VC Obetta , CO Okorie-Kanu , JI Eze. Comparative efficacy of Toltrazuril, Amprolium and Embazine Fort against mixed Eimeria specieses infection in broilers. Nigerian vet. Journal. 2011;32(3):214217.

25. Anosa GN , Okoro OJ. Anticoccidial activity of the Methanolic extract of Musa paradisiacal root in chickens. Trop. Anim. Hlh prod. 2011;43(1):245-248 doi: 10.1007/s11250-010-9684-1. 